\title{
Performance characteristics of a conceptual ring-shaped spar-type VLFS with double-layered perforated-wall breakwater
}

\author{
Yufeng Kou ${ }^{\mathrm{a}, \mathrm{b}}$, Longfei Xiao ${ }^{\mathrm{a}, \mathrm{b}, *}$, Longbin $\mathrm{Tao}^{\mathrm{c}}$, Tao Peng ${ }^{\mathrm{a}, \mathrm{b}}$ \\ a State Key Laboratory of Ocean Engineering, School of Naval Architecture, Ocean and Civil Engineering, Shanghai Jiao \\ Tong University, Shanghai 200240, China \\ ${ }^{\mathrm{b}}$ Collaborative Innovation Center for Advanced Ship and Deep-Sea Exploration, Shanghai Jiao Tong University, Shanghai \\ 200240, China \\ ${ }^{\mathrm{c}}$ Department of Naval Architecture and Marine Engineering, University of Strathclyde, Glasgow, G11XQ, United Kingdom
}

\begin{abstract}
A ring-shaped spar-type Very Large Floating Structure (VLFS) is proposed as an intermediate base for supporting deepwater resource exploitation far away from the coast line. The proposed VLFS is composed of eight rigidly connected deep-draft spar-type modules and an inside harbor. A double-layered perforated-wall breakwater is vertically attached to the VLFS and pierces through the water surface to attenuate the wave energy in the inside harbor. The hydrodynamic performance characteristics of the ring-shaped VLFS was experimentally evaluated in the present study, focusing on the motion responses, wave elevations, and wave run-ups. The natural periods of the motions in vertical plane were determined to be larger than $40 \mathrm{~s}$, which is much larger than common wave periods. This enhanced the motion performance in vertical plane and afforded favorable habitation and operation condition on the VLFS. A large surge damping was induced by the vertical breakwater, which tended to significantly affect the surge and pitch motions, but had a negligible effect on the heave motion. The component frequencies of the wave elevations in the inside harbor and the wave run-ups were identical with those of the incident waves. The wave attenuation was frequency-dependent and effective for the common wave frequencies, with a smaller loss coefficient observed in higher sea state. The wave attenuation and wave run-ups tended to improve in the absence of the leeward walls.
\end{abstract}

Key words: Very Large Floating Structure; breakwater; motion response; wave attenuation; wave run-up

\footnotetext{
* Corresponding author at: State Key Laboratory of Ocean Engineering, Shanghai Jiao Tong University, 800 Dongchuan Rd., Shanghai 200240, China.

E-mail addresses: kouyufeng@sjtu.edu.cn (Y.Kou), xiaolf@sjtu.edu.cn (L. Xiao), longbin.tao@strath.ac.uk (L. Tao), pengtao@sjtu.edu.cn (T. Peng).
} 


\section{Introduction}

Various concepts of Very Large Floating Structure (VLFS) composed of different types of modules have been proposed for a variety of applications such as floating airports, mobile offshore bases, floating bridges, floating fuel storage facilities, floating piers, floating offshore aquacultures, offshore renewable energy bases, and even floating cities [1]. Among the novel concepts, pontoon-type and semisubmersible-type VLFSs have been mostly investigated in industry and the academia [2].

The pontoon-type VLFS is a simple flat-box structure that appears like a giant plate floating on the water surface. Owing to its significant wave-induced hydroelastic response, it is most suitable for applications inside harbors or sheltered coastal formations with mild sea state. The Megafloat is a typical pontoon-type VLFS and has been reported to be effective, competitive, and suitable for development in protected waters such as large bays [3]. Comprehensive studies and onsite experiments have been conducted to demonstrate the technologies of the Megafloat [4]. In addition to studies on the traditional rectangular type [5,6], Hamamoto and Fujita [7] also analyzed L-shaped, T-shaped, C-shaped, and X-shaped VLFSs. Hexagonal and circular VLFSs have also been tested and investigated $[8,9]$.

The semisubmersible-type VLFS not only utilizes the low waterline area columns to support the long-length deck but also uses the submerged pontoons to maintain the constant buoyancy, bringing about the reduction of the effects of waves and the wave-induced motion response. This type of VLFS is thus suitable for applications in deepwater open seas with large waves. The Mobile Offshore Base (MOB) is a typical semisubmersible-type VLFS with a length of $2 \mathrm{~km}$ that accommodates conventional take-off and landing of aircrafts [10]. Several studies have been conducted on its hydrodynamic properties, flexible inter-module connectors, hydroelastic response in ocean waves, probabilistic design, and multiple module dynamic positioning [11]. In addition, Rognaas et al. [12] described a single-hull MOB that consisted of an 890-m central concrete core and long steel cantilever extensions that afforded the required deck length. They concluded that fatigue was not an issue of the concrete hull, which has a design life of 100 years. Manage et al. [13] reported feasibility studies on a VLFS with sails and several wind turbines as a sailing-type offshore wind farm. The VLFS has self-mobile and stationkeeping capabilities, which are enabled by a sail control system and the semi-submersible hull structure.

Owing to the large horizontal dimensions and relatively small draft, a VLFS deforms as an elastic plate floating on the water surface and experiences significant wave-induced hydroelastic response. Many innovative methods have thus been proposed for minimizing the hydroelastic motions and loads [14]. Bottom-founded-type or floating-type breakwaters, even the body-attached porous plates are conventionally used to attenuate the wave 
forces that act on a VLFS [15,16,17]. The installation of an Oscillating Water Column (OWC) device near a pontoon-type VLFS has also been proposed to effectively reduce the hydroelastic response and enable the use of the VLFS in open seas [18]. The use of air cushions for support is another innovative approach to reduce the wave-induced moments and structural loads of a VLFS, and the magnitude of the reduction is determined by the size of the air cushion [19,20]. Tay and Wang [21] investigated two different VLFS geometries in head seas and found that the hydroelastic response could be significantly reduced by modifying the plan shape. An innovative solution has been proposed and found to be effective for reducing the hydroelastic response and stress resultants of a pontoon-type VLFS, by positioning the flexible line connectors suitably and utilizing gill cells appropriately[22,23]. Furthermore, Nishi and Murai [24] proposed an optimal combination of a pontoon-type and semisubmersible-type VLFS to reduce the hydroelastic response.

Another innovative approach is the use of deep-draft modules such as spars, which are characterized by super stability and favorable vertical motions compared to other floating structures [25,26]. A ring-shaped VLFS that uses such deep-draft spar-type modules has been conceptually designed and is referred to as an Ultra-Large Floating System (ULFS) [27]. It includes eight deep-draft spar-type modules that form the intermediate base of the ring-shaped floating structure, which is used for supporting ultra-deepwater oil and gas exploitation. The intended functions of the floating structure include habitation, supplies storage and transfer, equipment maintenance, work boats shelter, and other logistic support.

One of the key features of the ring-shaped spar-type VLFS is the use of a double-layered perforated-wall breakwater to reduce the wave energy in the inside harbor. Owing to the complicated wave-wave and wavestructure interactions, the breakwater tends to significantly affect the hydrodynamic performance of the VLFS, including wave reflection, diffraction and transmission, energy dissipation, wave run-up, motion response, and mooring loads. The effect is mostly determined by the porosity and the height of the breakwater, and also the distance between two layers of perforated-walls. Although perforated-wall breakwaters with various novel configurations have been comprehensively investigated toward meeting practical requirements and achieving broad application in coastal engineering $[28,29,30]$, there have been only a few studies on floating structures with perforated-wall breakwaters [31,32]. In the past study, six breakwater configurations with different combinations of porosities were used to experimentally investigate the effect of the porosity on the hydrodynamic performances of the ring-shaped VLFS [33]. It is found that the wave loss coefficient, wave run-up, mooring force, and surge motion increase significantly with decreasing porosity, while the vertical motions remain unaffected. 
In this study, the global performance of the ring-shaped spar-type VLFS with a determined-porosity perforated-wall breakwater is further evaluated. In addition, the damping effect of the breakwater on the motions of the VLFS and the influence of the height of the breakwater on the global performance are investigated. A series of motion decay tests, white noise wave tests, and irregular wave tests were performed. The motion characteristics and response, wave elevations, wave energy attenuation, wave run-ups, and the effects of the breakwater on these performance characteristics were discussed by conducting spectral and statistical analyses. Unlike the concepts of pontoon-type and semisubmersible-type VLFSs, the ring-shaped VLFS consists of eight deep-draft spar-type modules with rigid connectors and thus the hydroelastic response is neglected because of little effects on the global performance.

\section{Experiment and data analysis method}

\subsection{Conceptual design and models}

The conceptual design of a ring-shaped VLFS has an outer circumference of $1256 \mathrm{~m}$ and a deep draft of 150 $\mathrm{m}$. It consists of eight deep-draft spar-type modules with rigid connectors. The VLFS can be opened as two semiring parts to let the work boat come into the inside harbor. The opening and closing of the VLFS during docking can be accomplished by the detachable connectors between two adjacent modules. Every module has a breakwater consisting of one set of double-layered porous plates with rectangular openings, and the porous plates are vertically attached to the columns of the module and pierce through the water surface. Eight sets of doublelayered porous plates form the entire perforated-wall breakwater with the height of $85 \mathrm{~m}$, which is an important part of the proposed VLFS to cause wave dissipation and decrease the transmitted waves in the inside harbor. As a result, the ring-shaped VLFS can function as material reserves, inside refuge harbor for work boats, housing, and landing pads for helicopters. The VLFS and module models are built for wave test according to the linear scale ratio of 1:80, as shown in Fig.1 (a) and (b). Table 1 lists the main details of the full scale and model scale conceptual VLFS. As it can be seen, the model is also very large, having the circumference of $15.7 \mathrm{~m}$, the draft of $1.875 \mathrm{~m}$, and the weight of $2477 \mathrm{~kg}$.

With regard to the attached breakwater, the uniform distance between the outer and inner plate layers is $24 \mathrm{~m}$ in full scale, which represents the width of the breakwater. The vertical dimensions of the outer and inner porous plate layers are the same, but the horizontal dimension of the inner layer is smaller. The sizes and distributions of the rectangular openings of the outer and inner porous plates are also different, resulting in different porosities. The porosity $\mu$ can be defined as 


$$
\mu=\frac{S_{\mathrm{p}}}{S_{1}+S_{\mathrm{p}}}
$$

where $S_{\mathrm{p}}$ is the area of an opening and $S_{1}$ is the plate area between adjacent openings. Based on the previous study [33], the porosities of the outer and inner plates are determined as 0.24 and 0.16 , respectively. There are 132 and 120 rectangular openings in each set of outer and inner porous plates. Fig. 2 shows the details of the outer and inner porous plates in model scale. The parameters of the physical models, including the weight, center of gravity, and roll/pitch radius of gyration, were adjusted to match the target values before model tests.

\subsection{Experimental campaign or set-up}

To investigate the hydrodynamic performance characteristics of the ring-shaped VLFS, an experimental study was conducted in the Deepwater Offshore Basin of Shanghai Jiao Tong University in China. The basin is $50 \mathrm{~m}$ long, $40 \mathrm{~m}$ wide, and with a maximum effective water depth of $10 \mathrm{~m}$. A large-area movable floor allows the flexible modeling of water depths of $0 \sim 10 \mathrm{~m}$. A secondary movable floor in the deep pit, which has a diameter of $5 \mathrm{~m}$, further enables the modelling of water depths of $10 \sim 40 \mathrm{~m}$. Various conditions can be modeled in the basin, including collinear and non-collinear waves, currents, and winds, which are simulated by two multi-flap wave generators, a deepwater global current generating system, and an axial wind fan matrix, respectively. The capabilities of the basin include the significant wave height of up to $0.3 \mathrm{~m}$, the surface current velocity of up to $0.4 \mathrm{~m} / \mathrm{s}$, and the mean wind speed of up to $10 \mathrm{~m} / \mathrm{s}$.

The experimental campaign included free decay tests, white noise wave and irregular wave tests. The free decay tests were conducted with the VLFS model and the isolated module model to evaluate the motion period and damping. All white noise wave and irregular wave test cases considered in the present study are listed in Table 2. The white noise wave test with the VLFS model was performed to obtain the transfer functions of the motion response and the wave elevation, referred to Case 1. Besides, the white noise wave test for the module with the breakwater was compared with that for the module without the breakwater to reveal the effect of the breakwater on the transfer functions of the motion response, referred to Case 6 and Case 7. The irregular wave tests were carried out to evaluate the global performance of the ring-shaped VLFS in the 1-year and 100-year waves in the South China Sea, referred to Case 2 and Case 3. For comparative investigation on the effect of the wave reflection by the vertical perforated walls in the inside harbor, Case 4 was performed using the VLFS without two sets of the leeward walls, which are included in two downstream modules, as shown in Fig.3. In Case 5, the VLFS with a shorter breakwater $\left(H_{\mathrm{b}}=60 \mathrm{~m}\right)$ was used by cutting off the lower part of the breakwater 
model to comparatively investigate the global effect of the height of the breakwater. The mass, center of gravity and roll/pitch radius of gyration were kept the same while the breakwater was changed. The duration of each wave test was approximately 20.2 minutes, which corresponds to 3 hours in the prototype.

Experimental set-up in the basin is shown in Fig.3. The equilibrium position of the VLFS model in still water was placed at the center of the basin. A four-slack-line horizontal mooring system was used to restrain the VLFS model in its equilibrium position by resisting the slowly varying wave drift forces. The attachment points of the slack lines were set at the elevation of the water surface so that the lines lay on the water surface. The angle between each slack line and the $\mathrm{X}$ axis of the VLFS is $45^{\circ}$. The length, axial stiffness and pretension of each slack line are $34 \mathrm{~m}, 12.82 \mathrm{~kg} / \mathrm{m}$ and $2 \mathrm{~kg}$ in model scale, respectively. The similar horizontal mooring system was applied in the test of the module model, where the axial stiffness and pretension of each slack line are 3.57 $\mathrm{kg} / \mathrm{m}$ and $0.5 \mathrm{~kg}$ in model scale, respectively.

The motion response, wave elevation, and wave run-up were measured in all wave tests. A non-contact optical tracking system by Qualysis ${ }^{\circledR}$ was used to capture the six degrees of freedom motions of the model. Seven resistance-type wave probes were used to measure the wave elevations relative to the model and the wave elevations in the basin near the model, as shown in Fig.3. The wave probes WP1 and WP7 were fixed $5 \mathrm{~m}$ away from the VLFS model in the basin to measure the wave elevations at the upstream and the lateral side of the structure, while the wave probe WP4 was located at the center of the VLFS model to measure the wave elevation in the inside harbor. In order to measure the wave run-ups, the wave probes WP2, WP3, WP5 and WP6 were all fixed on the VLFS model with the horizontal distance of $1.5 \mathrm{~cm}$ from the structure. The outer and inner wave run-ups at the forward walls were measured by the wave probes WP2 and WP3, while those at the lateral walls were measured by the wave probes WP5 and WP6. The measurement by the wave probe WPi was represented as $\mathrm{Wi}(\mathrm{i}=1,2, \ldots, 7)$ in the data analyses.

Prior to placing a model in the basin, three wave probes were installed in the basin to calibrate the specified waves. The power spectrum densities of the calibrated waves match the target very well, as shown in Fig.4, and thus the generated waves in the wave basin have good quality. The calibrated waves were then considered as the incident waves and they were used to analyze the measured data of the wave tests. The typical JONSWAP spectrum was applied to the simulation of the 1-year and 100-year waves, using the shape factors $\gamma$ of 2.0 and 2.4 , respectively.

\subsection{Data analysis method}


From the decay curve of the specific motion measured in the free decay test, the natural period can be calculated by averaging zero-crossing periods, and the damping coefficient defined as the ratio of the actual damping to the critical damping can be calculated by the logarithmic decrement method for amplitudes.

Regarding to the wave test, the sampled time series of the motions and the wave elevations can be statistically analyzed in the time domain to obtain the maximum, minimum and mean values and standard deviations. In addition, the power spectrum densities of the motions and the wave elevations can be derived by spectral analysis to estimate the response energy characteristics for a wide range of wave frequencies.

Furthermore, the results of the white noise wave test can be used to determine the frequency-dependent transfer functions of the wave elevations. For W1, W4 and W7, the transfer function denoted by $\kappa_{\mathrm{w}}(\omega)$ can be derived by comparing the power spectrum densities:

$$
\kappa_{\mathrm{w}}(\omega)=\sqrt{S_{\zeta}(\omega) / S_{\mathrm{i}}(\omega)}
$$

where $S_{\mathrm{i}}(\omega)$ and $S_{\zeta}(\omega)$ are the power spectrum densities of the incident wave and the wave elevation at the specific location, respectively.

For W2, W3, W5 and W6, the frequency-dependent transfer function of the wave run-up, $\kappa_{\mathrm{R}}(\omega)$, can be expressed as

$$
\kappa_{\mathrm{R}}(\omega)=\sqrt{S_{\mathrm{R}}(\omega) / S_{\mathrm{i}}(\omega)}
$$

where $S_{\mathrm{R}}(\omega)$ is the power spectrum density of the wave run-up at the specific location. The frequencydependent transfer function of the motion can be calculated by the similar method.

With regard to the irregular wave tests corresponding the 1-year and 100-year waves, for the quantitative estimation of the wave attenuation, the loss coefficient $K_{\mathrm{L}}$ can be defined and calculated by

$$
K_{\mathrm{L}}=\sqrt{1-K_{\mathrm{w}}^{2}}=\sqrt{1-E_{\mathrm{w}} / E_{\mathrm{i}}}
$$

where $E_{\mathrm{i}}$ and $E_{\mathrm{w}}$ are the total energies of the incident wave and the inside wave elevation W4, respectively, and are given by

$$
\begin{aligned}
& E_{\mathrm{i}}=\int_{0}^{\infty} S_{\mathrm{i}}(\omega) d \omega \\
& E_{\mathrm{w}}=\int_{0}^{\infty} S_{\mathrm{w}}(\omega) d \omega
\end{aligned}
$$


Similarly, from the power spectrum density of the wave run-up at specified location, the total wave run-up energy $E_{\mathrm{R}}$ and the coefficient $K_{\mathrm{R}}$ can be estimated using

$$
\begin{aligned}
& E_{\mathrm{R}}=\int_{0}^{\infty} S_{\mathrm{R}}(\omega) d \omega \\
& K_{\mathrm{R}}=\sqrt{E_{\mathrm{R}} / E_{\mathrm{i}}}
\end{aligned}
$$

\section{Results and discussions}

\subsection{Natural period and damping}

The natural periods and non-dimensional damping coefficients were determined by the decay tests. The results for both the VLFS and the module with the breakwater are compared in Table 3. As can be observed, the natural periods of the motions in vertical plane are substantially larger than dominant wave periods owing to the very large masses of the structure. For the VLFS, the natural frequencies of the heave and pitch motions are 0.156 and $0.131 \mathrm{rad} / \mathrm{s}$, respectively, which are clearly lower than the peak wave frequencies of the 1-year and 100-year irregular waves, so the wave-induced motion response in vertical plane should be small. Based on the test results of the module, the breakwater increased both the natural period and the damping of the roll and pitch motions, while the effect on the heave motion was negligible. Fig.5 obviously shows that the pitch of the module decays rapider with a larger period than that without the breakwater. Attributing to the breakwater, the damping coefficient of the surge motion is quite large, and reaches to 0.40 and 0.47 for the module and the VLFS, respectively. As can be clearly seen in Fig.6, the surge motion of the VLFS tends to decay slower with a smaller natural period, when the height of the breakwater was reduced to $60 \mathrm{~m}$ by using the same model of shorter breakwater shown in Table 2. This indicates that the breakwater with vertically perforated walls increases both the viscous damping and the added mass of the horizontal motions, which is similar to the effect of the damping plate on the vertical motions of a spar platform $[34,35]$.

\subsection{Motion transfer function}

The result of the white noise wave test Case 1 was used to obtain the linear transfer functions of the motions for a wide range of wave frequencies, as shown in Fig.7 for the VLFS. With regard to the heave and pitch motions, it can be seen that the values of the transfer functions for the frequencies higher than $0.2 \mathrm{rad} / \mathrm{s}$ are quite small. The peak values are located at the natural frequency, at which the motion resonance occurs. Considering that common wave frequencies in practice are higher, the wave-induced motions in vertical plane can be 
reasonably expected to be small.

To evaluate the effect of the breakwater, the white noise wave tests Case 6 for the module and Case 7 for the module without its breakwater were conducted, the results of which are compared in Fig.8. As can be observed, the breakwater is mostly effective for the motions with frequencies lower than $0.25 \mathrm{rad} / \mathrm{s}$. For wave frequencies higher than $0.25 \mathrm{rad} / \mathrm{s}$, the effect of the breakwater on the motion response is negligible. Because ocean waves in practice always have frequencies higher than $0.25 \mathrm{rad} / \mathrm{s}$, the breakwater tends to have little effect on the wave frequency motions. The effect is, however, significant for low-frequency motions, for which smaller responses can be observed for the module. It is noted that the perforated-wall breakwater can not only increase the damping to decrease the motion response, but also increase the wave forces to increase the motion response. For the lowfrequency motions, the values of the transfer functions for the module with the breakwater are obviously smaller than those for the module without the breakwater. It means the damping effect of the breakwater tends to be greater than the effect of the additional wave forces due to the breakwater, finally resulting in the combined effect of reducing the response. With regard to the wave frequency motions, there is no obvious difference in the transfer functions, which means the damping effect of the breakwater on reducing the motion response tends to be counterbalanced by the increment of additional wave forces due to the breakwater.

\subsection{Motion response}

The results of the irregular wave tests were used to determine the total motion responses corresponding to full frequency range, and were further filtered to obtain the Low-Frequency (LF) and High-Frequency (HF) responses. The cut-off frequency was set at $0.2 \mathrm{rad} / \mathrm{s}$, which is clearly lower than the wave frequencies containing significant amounts of wave energies.

The statistics of the total, LF, and HF responses of the surge, heave, and pitch motions are presented in Table 4 for both Case 2 in the 1-year wave and Case 3 in the 100-year wave. The table reveals that, not only the surge motion, but also the heave and pitch motions are mainly low-frequency responses. For the surge motion, the standard deviation of the LF response is close to $100 \%$ of that of the total response, and the HF response is relatively negligible. The standard deviations of the LF and HF responses are approximately $88 \%$ and $60 \%$ of that of the total response for heave motion, while the percentages are approximately $82 \%$ and $70 \%$ for pitch motion, respectively. It is in agreement with the observations on the transfer functions, and the motion with low frequencies dominate the motion response even under the 100-year wave condition. The statistics of the heave and pitch motions clearly indicate that the motions in vertical plane are small. Even under the 100-year wave 
condition, the maximum amplitudes of the heave and pitch motions are $0.67 \mathrm{~m}$ and $1.53^{\circ}$, respectively. The good motion performance in vertical plane tends to favor habitation and operations on the VLFS.

With regard to the energy distributions of the motion response, the power spectra of the surge, heave, and pitch motions for Case 2 in the 1-year wave condition are also shown in Fig.9. It can be clearly observed that the peak motion responses are concentrated on respective low natural frequencies. Furthermore, only one peak spectrum frequency exists and is equivalent to the natural frequency for the surge and heave motions, respectively, while no peak spectrum frequency can be observed within the wave frequencies, as shown in Fig.9 (a) and (b). However, there are evidently three peak spectrum frequencies for the pitch motion in Fig.9 (c), one of which corresponding to the maximum spectrum energy is equivalent to the natural frequency of the pitch motion, while the lowest one is equivalent to the natural frequency of the surge motion, and the third one is close to the peak wave frequency. It indicates that the coupling with the surge motion affects the pitch motion, and that the linear wave-induced pitch motion is significant.

The statistics and LF spectra of the surge, heave, and pitch for Case 3, Case 4 and Case5 are presented and compared in Table 5 and Fig.10 to reveal the effect of the breakwater on motions. It can be observed that the heave response is almost consistent for the different breakwaters. Both the mean value and variance of the surge motion clearly decrease with decreasing the breakwater height and without the leeward walls, which indicates that the breakwater with the vertical porous walls significantly affects the horizontal motion response owing to the change in the wave interaction forces. The results of the surge motion also imply that the wave drift force on the VLFS decreases with decreasing the breakwater height and without the leeward walls. The peak spectrum frequency of the surge motion varies with the conditions in Fig.10 (a), while those of the heave and pitch motions are constant in Fig.10 (b) and (c). This indicates that the breakwater affects not only the damping, but also the added mass of the surge. A breakwater with shorter perforated walls induces lower added mass of the surge, resulting in a higher peak spectrum frequency. The pitch motion increases without the leeward walls but remains almost the same with decreasing the height of the breakwater. It indicates that the wave-induced pitch moment is not affected by reducing the height of the breakwater, although the reduction can be used to decrease the horizontal wave force. However, the breakwater without the leeward walls becomes asymmetric, thus increasing the wave-induced pitch moment, although this also tends to decrease the horizontal wave force.

\subsection{Wave elevation and attenuation}

As an intermediate base for supporting offshore resource exploitation, the ring-shaped VLFS is used for the 
mooring and sheltering of work boats. Hence, the wave elevations are key performance factors that require evaluation. The wave field around the ring-shaped VLFS is typically represented by the inside wave elevation W4, the upstream wave elevation W1, and the lateral wave elevation W7. Particular focus is on the wave elevation W4 because it represents the most significant performance characteristic of the perforated-wall breakwater. The wave elevation W4 was used to analyze the wave energy attenuation, by comparison with the outside wave elevations W1 and W7, and also the incident waves obtained during the wave calibration without any model in the basin.

The frequency-dependent transfer functions of the wave elevations W1, W4 and W7 are derived from the white noise test Case 1, as shown in Fig.11. It can be clearly observed that the transfer function values of W4 are almost smaller than 1.0, which means the wave energy attenuation is obvious in the inside harbor of VLFS. In addition, the transfer function values oscillate with the wave frequency. This is a critical feature of the ringshaped breakwater, which is characterized by both wave reflection and transmission and their interaction in the inside harbor, with the tendency to induce different wave attenuations. Similar phenomenon was reported for the wave reflection by a perforated wall breakwater [28] and the wave forces on a porous structure [30]. For the frequencies lower than $0.3 \mathrm{rad} / \mathrm{s}$, the values are close to 1.0 , which indicates the absence of wave attenuation because of the difficulty of dissipating a long wave by the vertical perforated-wall breakwater and large wave transmission for the long waves. The transfer function values for the other two peak frequencies of $0.48 \mathrm{rad} / \mathrm{s}$ and $0.64 \mathrm{rad} / \mathrm{s}$ are also close to 1.0 , which again indicates the absence of wave attenuation. The wave attenuation is better for the frequencies between 0.7 and $1.4 \mathrm{rad} / \mathrm{s}$. At the frequencies higher than $1.4 \mathrm{rad} / \mathrm{s}$, the transfer function values become close to 1.0 again, indicating the disappearance of wave attenuation. Since the wave frequencies commonly range between 0.4 and $1.4 \mathrm{rad} / \mathrm{s}$, the wave attenuation tends to be evident and the breakwater works well as a result of the wave dissipation by the two-layered perforated walls. With regard to the outside wave elevations, it can be observed that the upstream wave W1 is very close to the incident wave while the lateral wave W7 is slightly lower. This indicates a tendency for the wave diffraction and radiation in the upstream and lateral side of VLFS to be insignificant.

The wave elevations for Case 2 in the 1-year wave and Case 3 in the 100-year wave are reflected by the power spectrum densities, as shown in Fig.12. It can be seen that both the outside and inside wave energies are distributed within the same frequency range as the incident waves. The peak spectrum frequency of wave elevation W4 in the inside harbor is slightly smaller than that of the incident wave under the 1-year condition in Fig.12 (a), but the same frequency applies to the 100-year condition in Fig.12 (b). Wave attenuation is evident 
from a comparison of the spectrum values with the incident wave within the effective frequency range, and the attenuation can be observed to be frequency-dependent. Unlike the incident wave which has only one peak frequency, the inside wave W4 has at least two peak values, especially under the 1-year condition. This is attributed to the wave reflection by the inner vertical walls of the breakwater, because the wave radiation is expected to be of low frequency and insignificant owing to the low-frequency motions. Under the 1-year condition as shown in Fig.12 (a), the outside wave is close to the incident wave at the upstream side, while it is smaller in the lateral direction. Under the 100-year condition as shown in Fig.12 (b), the outside wave is larger than the incident wave at the upstream side, while it is of almost the same size in the lateral direction. This indicates that wave diffraction and radiation as well as the outside waves tend to be enhanced in a higher sea state.

The power spectra of the wave elevation W4 in the inside harbor for different breakwater configurations under the 100-year wave condition are compared in Fig.13, referred to Case3, Case4 and Case5. It can be seen that the inside wave energies differ much from each other. The energy is particularly low in Case 4 for the VLFS without the leeward walls, in which case the inside waves tend to be transmitted downstream and not reflected in the inside harbor. This further demonstrates that the inside wave energy is produced by not only wave transmission, but also wave diffraction and reflection by the vertical walls.

The loss coefficients were calculated by Eq. (4) and presented in Table 6. A smaller loss coefficient was obtained for higher sea states owing to the wave diffraction and reflection in the inside harbor. This condition can, however, be improved by omitting or reducing the height of the leeward walls.

\subsection{Wave run-ups}

Wave run-up is one of the critical issues of both the design and utilization of deepwater structures exposed to harsh environments. The wave run-up can be strongly non-linear in the vicinity of the structure owing to the various complex wave-hull interactions. The wave run-up energy is generated by not only the wave incidence and the wave-hull interaction, but also by the motions of the hull in vertical plane. Its characteristics were evaluated in this study by comparing the measured relative wave elevations W2, W3, W5 and W6 with the incident wave.

The transfer functions of the wave run-ups at four typical locations are derived from the white noise test Case 1, as shown in Fig.14. As can be observed, the values of the transfer functions of the wave run-ups are generally higher than 1.0 for W2 and W6 outside the breakwater, but less than 1.0 for W3 and W5 inside the breakwater. 
In addition, a uniform peak frequency of $0.16 \mathrm{rad} / \mathrm{s}$ for all four measurements exists and is equivalent to the natural frequency of heave motion. This indicates that the wave run-up energies in the vicinity of this frequency are mainly generated by the vertical motions of the VLFS at these locations. Owing to the wave dissipation of the breakwater, the inner wave run-ups are smaller than the outer ones within the frequency range of $0.5 \sim 1.5$ $\mathrm{rad} / \mathrm{s}$.

Fig. 15 shows the power spectra of the wave run-ups for Case 2 in the 1 -year wave and Case 3 in the 100-year wave. The wave run-up energy is mainly distributed within the same frequency range as the incident wave. A part of the energy corresponding to the natural frequencies of the heave and pitch motions exists in the lowfrequency range around $0.13 \mathrm{rad} / \mathrm{s}$. Owing to relatively small magnitude of the low-frequency energy induced by the motions of the floater in vertical plane, they are neglected and only the response within the wave frequency range is considered in the present discussion of the wave run-up characteristics. The peak energy frequencies are almost constant and are equivalent to those of the incident waves under both the 1-year and 100-year conditions, except W3 at the forward inner location. The outer wave run-ups are more significant than the inner ones owing to the wave attenuation by the breakwater, as shown in both Fig.15 (a) and (b). The forward outer wave run-ups are evidently larger than the lateral ones, indicating that the upstream wave reflection is more dominant than the lateral wave diffraction. Conversely, the forward inner wave run-ups are smaller than the lateral ones.

The wave run-ups for different breakwater configurations under the 100-year wave conditions are compared in Fig.16, referred to Case3, Case4 and Case5. It can be seen in Fig.16 (a) and (d) that the effects of the configuration on the wave run-ups are significant at the forward outer and lateral inner locations. The forward outer wave run-up evidently decreases with decreasing the height of the breakwater. Moreover, the lateral inner wave run-up tends to decrease significantly in the absence of the leeward walls because of no wave reflection by them.

The determined coefficients are obtained by Eq. (8) and presented in Table 7. As can be observed from the table, the wave run-up coefficients are slightly larger for higher sea state. This is due to the wave diffraction and reflection in the inside harbor, and the wave run-up at the special locations can be improved by omitting or reducing the height of the leeward walls.

\section{Conclusions}

The motion performance, wave elevations, and wave run-ups of a ring-shaped VLFS with a perforated-wall breakwater were experimentally investigated. The natural periods of both the horizontal and vertical motions are 
found to be larger than $40 \mathrm{~s}$, which is much larger than the common wave periods. Consequently, the values of the motion transfer functions at the wave frequencies are small and the motion response is mainly low-frequency. The maximum amplitudes of the heave and pitch are $0.67 \mathrm{~m}$ and $1.53^{\circ}$ under the 100 -year wave condition, indicating excellent motion performance in vertical plane and favorable habitation and operation conditions. Three peak spectrum frequencies of the pitch are observed, one of which is due to coupling with the surge. The vertical breakwater has a significant effect on the low-frequency motions. However, the effect on the wave frequency response tends to be negligible.

Wave attenuation by the breakwater appears to be negligible at the wave frequencies lower than $0.3 \mathrm{rad} / \mathrm{s}$ and higher than $1.4 \mathrm{rad} / \mathrm{s}$, but effective in between with the exception of at 0.48 and $0.64 \mathrm{rad} / \mathrm{s}$. Due to wave reflection by the vertical breakwater, the power spectrum densities of the wave elevation in the inside harbor of the VLFS have at least two peak values, which determines that the wave attenuation by the breakwater is frequency-dependent. The loss coefficient is smaller in higher sea state and tends to increase with the omission or reduction of the height of the leeward walls.

The wave run-up energy is observed to be concentrated within the same frequency range as that of the incident wave, and there are small additional parts at the natural frequencies of the heave and pitch motions. The values of the wave run-up transfer functions are found to be generally larger than 1.0 outside the VLFS, and smaller than 1.0 inside it. The forward outer wave run-ups are larger than the lateral wave run-ups, indicating that the upstream wave reflection is more dominant than the lateral wave diffraction. Conversely, the forward inner wave run-ups are clearly smaller than the lateral ones. The wave run-up coefficients are slightly larger in higher sea state owing to the wave reflection in the inside harbor.

The ring-shaped spar-type VLFS experiences excellent motion performance in vertical plane which can afford favorable habitation and operation conditions. The double-layered perforated-wall breakwater effectively reduces the wave energy in the inside harbor of the VLFS. However, the breakwater attracts more horizontal wave force, which introduces additional requirements in the design of the mooring system. In order to improve the global performance, the configuration of the breakwater needs to be further optimized. In addition, the wave elevations at different locations in the inside harbor differ a lot, which should be taken into consideration when the work boat docks inside.

\section{Acknowledgments}

The authors would like to acknowledge the support of the National Natural Science Foundation of China 
(Grant No. 51879158), the National High Technology Program (863 Program) of China (Grant No. 2008AA09A107), Chinese Offshore Oil Engineering Co. Ltd. (COOEC), and Chinese National Offshore Oil Company (CNOOC). The authors are also grateful to the anonymous reviewers whose valuable comments and suggestions have contributed to improving the manuscript.

\section{References}

[1] C.M. Wang, E. Watanabe, T. Utsunomiya, Very large floating structures, Taylor and Francis, Abingdon, Oxon, 2008.

[2] M. Lamas-Pardo, G. Iglesias, L. Carral, A review of Very Large Floating Structures (VLFS) for coastal and offshore uses, Ocean Eng. 109 (2015) 677-690. doi:10.1016/j.oceaneng.2015.09.012.

[3] H. Suzuki, Overview of Megafloat: Concept, design criteria, analysis, and design, Mar. Struct. 18 (2005) 111-132. doi:10.1016/j.marstruc.2005.07.006.

[4] S. Ohmatsu, Overview: Research on wave loading and responses of VLFS, Mar. Struct. 18 (2005) 149-168. doi:10.1016/j.marstruc.2005.07.004

[5] X.J. Chen, J.J. Jensen, W.C. Cui, S.X. Fu, Hydroelasticity of a floating plate in multidirectional waves, Ocean Eng. 30 (2003) $1997-2017$. doi:10.1016/S0029-8018(03)00020-9.

[6] M. Kashiwagi, A B-spline Galerkin scheme for calculating the hydroelastic response of a very large floating structure in waves, J. Mar. Sci. Technol. 3 (1998) 37-49. doi:10.1007/BF01239805.

[7] T. Humamoto, K. Fujita, Wet-Mode Superposition for Evaluating the Hydroelastic Response of Floating Structures with Arbitrary Shape, Proc. Twelfth Int. Offshore Polar Eng. Conf. Kitakyushu, Japan, May 26-31, 2002.3 (2002) 290-297.

[8] G. Zilman, T. Miloh, Hydroelastic buoyant circular plate in shallow water: A closed form solution, Appl. Ocean Res. 22 (2000) 191-198. doi:10.1016/S0141-1187(00)00011-0.

[9] E. Watanabe, T. Utsunomiya, C.M. Wang, L.T.T. Hang, Benchmark hydroelastic responses of a circular VLFS under wave action, Eng. Struct. 28 (2006) 423-430. doi:10.1016/j.engstruct.2005.08.014.

[10] K.R. McAllister, Mobile offshore bases - an overview of recent research. J. Mar. Sci. Technol. 2 (1997) 173-81.

[11] P. Palo, Mobile offshore base: Hydrodynamic advancements and remaining challenges, Mar. Struct. 18 (2005) $133-147$. doi:10.1016/j.marstruc.2005.07.007.

[12] G. Rognaas, J. Xu, S. Lindseth, F. Rosendahl, Mobile offshore base concepts concrete hull and steel topsides, Mar. Struct. 14 (2001) 5 23. doi:10.1016/S0951-8339(00)00019-8.

[13] H. Manabe, T. Uehiro, M. Utiyama, et al., Development of the floating structure for the Sailing-type Offshore Wind Farm, Ocean. MTS/IEEE Kobe-Techno-Ocean'08 - Voyag. Towar. Futur. OTO’08. (2008) 0-3. doi:10.1109/OCEANSKOBE.2008.4531100.

[14] C.M. Wang, Z.Y. Tay, Very large floating structures: Applications, research and development, Procedia Eng. 14 (2011) 62-72. doi:10.1016/j.proeng.2011.07.007.

[15] D.C. Hong, S.Y. Hong, S.W. Hong, Reduction of hydroelastic responses of a very-long floating structure by a floating oscillating-watercolumn breakwater system, Ocean Eng. 33 (2006) 610-634. doi:10.1016/j.oceaneng.2005.06.005.

[16] S. Singla, S.C. Martha, T. Sahoo, Mitigation of structural responses of a very large floating structure in the presence of vertical porous barrier, Ocean Eng. 165 (2018) 505-527. doi:10.1016/j.oceaneng.2018.07.045.

[17] Y. Cheng, G. Zhai, J. Ou, Numerical and experimental analysis of hydroelastic response on a very large floating structure edged with a 
pair of submerged horizontal plates, J. Mar. Sci. Technol. 20 (2015) 127-141. doi:10.1007/s00773-014-0269-y.

[18] E. Watanabe, T. Utsunomiya, C.M. Wang, Hydroelastic analysis of pontoon-type VLFS: A literature survey, Eng. Struct. 26 (2004) 245-256. doi:10.1016/j.engstruct.2003.10.001.

[19] J.A. Pinkster, E.J.A. M. Scholte, The behavior of a large air-supported MOB at sea, Mar. Struct. 14 (2001) $163-179$. doi:10.1016/S0951-8339(00)00044-7.

[20] T. Ikoma, K. Masuda, C.-K. Rheem, H. Maeda, Hydroelastic Behaviors of VLFS Supported by Many Aircushions With the ThreeDimensional Linear Theory, J. Offshore Mech. Arct. Eng. 134 (2012) 011104. doi:10.1115/1.4003697.

[21] Z.Y. Tay, C.M. Wang, Reducing hydroelastic response of very large floating structures by altering their plan shapes, Ocean Syst. Eng. 2 (2012) 69-81. doi:10.12989/ose.2012.2.1.069.

[22] C.M. Wang, D.C. Pham, K.K. Ang, Effectiveness and optimal design of gill cells in minimizing differential deflection in circular VLFS, Eng. Struct. 29 (2007) 1845-1853. doi:10.1016/j.engstruct.2006.10.010.

[23] R.P. Gao, C.M. Wang, C.G. Koh, Reducing hydroelastic response of pontoon-type very large floating structures using flexible connector and gill cells, Eng. Struct. 52 (2013) 372-383. doi:10.1016/j.engstruct.2013.03.002.

[24] T. Nishi, M. Murai, A Study on the Optimization for the Arrangement of Two Types of Supporting Columns for VLFS Using GA, 29th Int. Conf. Ocean. Offshore Arct. Eng. Vol. 3. (2010) 49-56. doi:10.1115/OMAE2010-20255.

[25] A.K. Agarwal, A.K. Jain, Dynamic behavior of offshore spar platforms under regular sea waves. Ocean Eng. 30 (2003) 487-516. doi: 10.1016/S0029-8018(02)00034-3.

[26] M.J. Downie, J.M.R. Graham, C. Hall, et al., An experimental investigation of motion control devices for truss spars, Mar. Struct. 13 (2000) 75-90. doi:10.1016/S0951-8339(00)00010-1.

[27] J.H. Liu, W.J. Zhong, H.Y. Zeng, K.L. Shen, New conceptual style of ultra large floating system, 31st Int. Conf. Ocean. Offshore Arct. Eng. Vol. 5. (2012) 311-318. doi: 10.1115/OMAE2012-83802.

[28] Y. Liu, Y.C. Li, B. Teng, Wave interaction with a perforated wall breakwater with a submerged horizontal porous plate, Ocean Eng. 34 (2007) 2364-2373. doi:10.1016/j.oceaneng.2007.05.002.

[29] K.D. Suh, J.K. Park, W.S. Park, Wave reflection from partially perforated-wall caisson breakwater, Ocean Eng. 33 (2006) $264-280$. doi:10.1016/j.oceaneng.2004.11.015.

[30] H. Song, L. Tao, Short-crested wave interaction with a concentric porous cylindrical structure, Appl. Ocean Res. 29 (2007) $199-209$. doi:10.1016/j.apor.2008.01.001.

[31] F. Zhao, W. Bao, T. Kinoshita, H. Itakura, Theoretical and Experimental Study on a Porous Cylinder Floating in Waves, J. Offshore Mech. Arct. Eng. 133 (2011) 011301. doi:10.1115/1.4001435

[32] S. Neelamani, J. Ljubic, Experimental study on the hydrodynamic performance of floating pontoon type breakwater with skirt walls, J. Offshore Mech. Arct. Eng. 140 (2018) 1-9. doi:10.1115/1.4038343.

[33] L. Xiao, Y. Kou, L. Tao, L. Yang, Comparative study of hydrodynamic performances of breakwaters with double-layered perforated walls attached to ring-shaped very large floating structures, Ocean Eng. 111 (2016) 279-291. doi:10.1016/j.oceaneng.2015.11.007.

[34] B. Molin, On the added mass and damping of periodic arrays of fully or partially porous disks, J. Fluids Struct. 15 (2001) $275-290$. doi:10.1006/jfls.2000.0338.

[35] L. Tao, D. Dray, Hydrodynamic performance of solid and porous heave plates, Ocean Eng. 35 (2008) $1006-1014$. doi:10.1016/j.oceaneng.2008.03.003. 


\section{List of Tables}

Table 1

Main details of the ring-shaped VLFS.

Table 2

Wave test cases. ( $H_{s}$ : significant wave height; $T_{p}$ : peak wave period.)

Table 3

The results determined by free decay tests.

Table 4

Statistics of the motion responses under the 1-year and 100-year wave conditions.

\section{Table 5}

Statistics of the motion responses for the VLFS with different breakwaters (100-year).

Table 6

Wave energy loss coefficients for different cases.

\section{Table 7}

Wave run-up coefficients for different cases. 
Table 1

Main details of the ring-shaped VLFS.

\begin{tabular}{lcccc}
\hline \multicolumn{1}{c}{ Parameter } & Symbol & Unit & Prototype & Model \\
\hline Outer/Inner diameter & $D_{\mathrm{o}} / D_{\mathrm{i}}$ & $\mathrm{m}$ & $400 / 328$ & $5.0 / 4.1$ \\
Height of main deck above keel & $H$ & $\mathrm{~m}$ & 185 & 2.3125 \\
Draft & $H_{\mathrm{d}}$ & $\mathrm{m}$ & 150 & 1.875 \\
Height of breakwater & $H_{\mathrm{b}}$ & $\mathrm{m}$ & 85 & 1.0625 \\
Breakwater bottom elevation & $H_{\mathrm{bb}}$ & $\mathrm{m}$ & 90 & 1.125 \\
Height of lower tank & $H_{\mathrm{t}}$ & $\mathrm{m}$ & 10.0 & 0.125 \\
Height of column & $H_{\mathrm{c}}$ & $\mathrm{m}$ & 165.0 & 2.0625 \\
Diameter of columns & $D_{\mathrm{cl}} / D_{\mathrm{c} 2}$ & $\mathrm{~m}$ & $24 / 14$ & $0.3 / 0.175$ \\
Displacement weight & $\Delta$ & $\mathrm{t}$ & 1300000 & 2.477 \\
Elevation of centre of gravity & $z_{\mathrm{G}}$ & $\mathrm{m}$ & 70.0 & 0.875 \\
Roll/Pitch radius of gyration & $K_{x x} / K_{y y}$ & $\mathrm{~m}$ & 138 & 1.725 \\
\hline
\end{tabular}




\section{Table 2}

Wave test cases. ( $H_{s}$ : significant wave height; $T_{p}$ : peak wave period.)

\begin{tabular}{cll}
\hline Case No. & \multicolumn{1}{c}{ Wave } & \multicolumn{1}{c}{ Model } \\
\hline 1 & White noise wave & VLFS, initial design \\
2 & 1 -year, $H_{s}=7.0 \mathrm{~m}, T_{p}=12.1 \mathrm{~s}$ & VLFS, initial design \\
3 & 100 -year, $H_{s}=13.8 \mathrm{~m}, T_{p}=16.1 \mathrm{~s}$ & VLFS, initial design \\
4 & 100 -year, $H_{s}=13.8 \mathrm{~m}, T_{p}=16.1 \mathrm{~s}$ & VLFS without leeward walls \\
5 & 100 -year, $H_{s}=13.8 \mathrm{~m}, T_{p}=16.1 \mathrm{~s}$ & VLFS with shorter breakwater \\
6 & White noise wave & Module with the breakwater \\
7 & White noise wave & Module without the breakwater \\
\hline
\end{tabular}




\section{Table 3}

The results determined by free decay tests.

\begin{tabular}{lccccccccc}
\hline & \multicolumn{2}{c}{ Natural period (s) } & \multicolumn{2}{c}{ Natural frequency (rad/s) } & \multicolumn{2}{c}{ Damping coefficient } \\
Model & \multicolumn{2}{c}{ Module } & VLFS & Module & VLFS & Module & VLFS \\
Breakwater & Yes & No & Yes & Yes & No & Yes & Yes & No & Yes \\
\hline Heave & 40.1 & 40.3 & 40.2 & 0.157 & 0.156 & 0.156 & 0.01 & 0.01 & 0.02 \\
Roll & 45.5 & 42.2 & 47.3 & 0.138 & 0.149 & 0.133 & 0.04 & 0.03 & 0.04 \\
Pitch & 74.9 & 56.9 & 48.0 & 0.084 & 0.110 & 0.131 & 0.12 & 0.03 & 0.03 \\
Surge & 259.6 & - & 438.6 & 0.024 & - & 0.014 & 0.40 & - & 0.47 \\
\hline
\end{tabular}


Table 4

Statistics of the motion responses under the 1-year and 100-year wave conditions.

\begin{tabular}{|c|c|c|c|c|c|c|c|}
\hline \multirow{2}{*}{\multicolumn{2}{|c|}{$\begin{array}{c}\text { Case No. } \\
\text { Item }\end{array}$}} & \multicolumn{3}{|c|}{ Case 2} & \multicolumn{3}{|c|}{ Case 3} \\
\hline & & Total & $\mathrm{LF}$ & $\mathrm{HF}$ & Total & LF & $\mathrm{HF}$ \\
\hline & Max. & 1.43 & 1.24 & 0.62 & 3.98 & 3.29 & 2.98 \\
\hline Surge & Min. & -13.46 & -13.26 & -0.58 & -62.06 & -60.86 & -3.15 \\
\hline \multirow[t]{3}{*}{ (m) } & Mean & -4.23 & -4.23 & 0.0 & -18.12 & -18.12 & 0.0 \\
\hline & SD. & 2.33 & 2.32 & 0.16 & 11.23 & 11.22 & 0.72 \\
\hline & Max. & 0.35 & 0.26 & 0.27 & 0.53 & 0.37 & 0.37 \\
\hline Heave & Min. & -0.35 & -0.28 & -0.27 & -0.67 & -0.54 & -0.36 \\
\hline \multirow[t]{3}{*}{ (m) } & Mean & -0.03 & -0.03 & 0.0 & -0.07 & -0.07 & 0.0 \\
\hline & SD. & 0.09 & 0.08 & 0.05 & 0.16 & 0.14 & 0.08 \\
\hline & Max. & 0.22 & 0.16 & 0.12 & 0.65 & 0.42 & 0.52 \\
\hline Pitch & Min. & -0.24 & -0.16 & -0.11 & -1.53 & -1.21 & -0.54 \\
\hline \multirow[t]{2}{*}{$\left(^{\circ}\right)$} & Mean & -0.01 & -0.01 & 0.0 & -0.07 & -0.07 & 0.0 \\
\hline & SD. & 0.06 & 0.05 & 0.03 & 0.21 & 0.17 & 0.13 \\
\hline
\end{tabular}




\section{Table 5}

Statistics of the motion responses for the VLFS with different breakwaters (100-year).

\begin{tabular}{lccc}
\hline Case No. & Case 3 & Case 4 & Case 5 \\
\hline Surge mean & -18.12 & -13.94 & -11.29 \\
Surge SD. & 11.23 & 9.98 & 8.66 \\
Heave SD. & 0.16 & 0.18 & 0.16 \\
Pitch SD. & 0.21 & 0.26 & 0.20 \\
\hline
\end{tabular}


Table 6

Wave energy loss coefficients for different cases.

\begin{tabular}{ccccc}
\hline Case No. & Case 2 & Case 3 & Case 4 & Case 5 \\
\hline$K_{\mathrm{L}}$ & 0.787 & 0.664 & 0.747 & 0.716 \\
\hline
\end{tabular}




\section{Table 7}

Wave run-up coefficients for different cases.

\begin{tabular}{ccccc}
\hline Case No. & Case 2 & Case 3 & Case 4 & Case 5 \\
\hline$K_{\mathrm{R} 2}$ & 1.296 & 1.364 & 1.469 & 1.284 \\
$K_{\mathrm{R} 3}$ & 0.611 & 0.714 & 0.737 & 0.716 \\
$K_{\mathrm{R} 5}$ & 0.759 & 0.761 & 0.688 & 0.808 \\
$K_{\mathrm{R} 6}$ & 1.064 & 1.072 & 1.022 & 1.053 \\
\hline
\end{tabular}




\section{List of Figures}

Fig.1. Physical models of the VLFS and the module.

Fig.2. Dimensions of the outer and inner porous plate in model scale (Unit: $\mathrm{mm}$ ).

Fig.3. Experimental set-up.

Fig.4. Calibration of the incident wave spectra.

Fig.5. Free decay curves of the pitch motion of the module.

Fig.6. Free decay curves of the surge motion of the VLFS.

Fig.7. Transfer functions of the motions of the VLFS (Case 1).

Fig.8. Transfer functions of the motions of the module.

Fig.9. Power spectra of the surge, heave, and pitch motions (Case 2, 1-year).

Fig.10. Comparison of the power spectra of the LF motions for the VLFS with different breakwaters (100-year).

Fig.11. Transfer functions of the upstream, inside, and lateral waves of the VLFS (Case 1).

Fig.12. Comparison of the upstream, inside, and lateral wave spectra of the VLFS with the incident wave.

Fig.13. Comparison of the wave spectra in the inside harbor for the VLFS with different breakwaters (100-year).

Fig.14. Transfer functions of the wave run-ups at various locations of the VLFS (Case 1).

Fig.15. Spectra of the wave run-ups at various locations of the VLFS.

Fig.16. Spectra of the outer and inner wave run-ups of the VLFS for different breakwaters (100-year). 


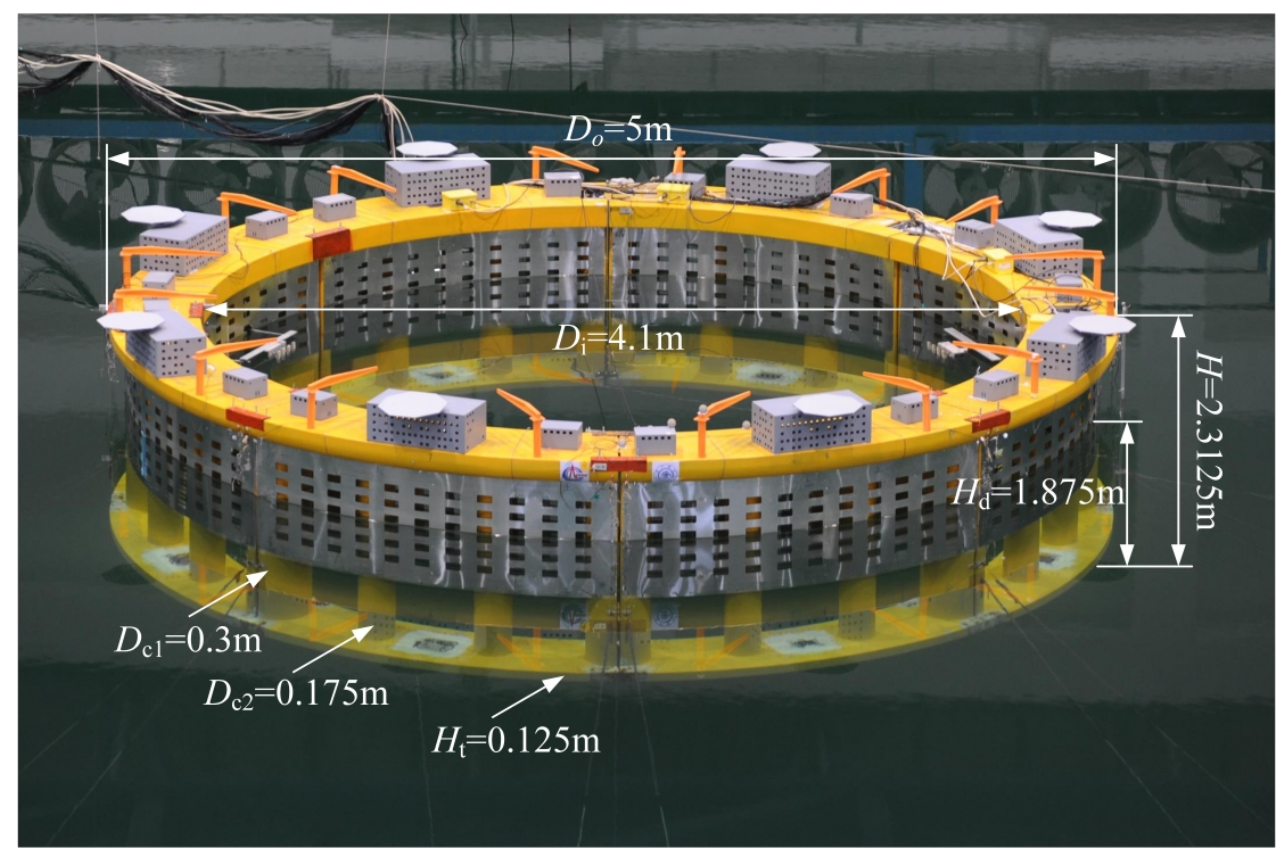

(a) The ring-shaped VLFS model

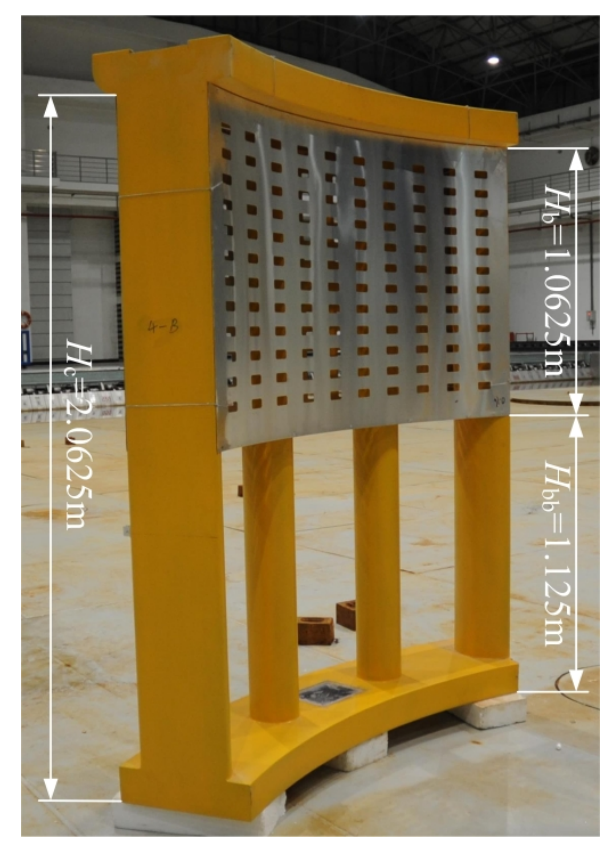

(b) The module model

Fig.1. Physical models of the VLFS and the module. 
1562.5

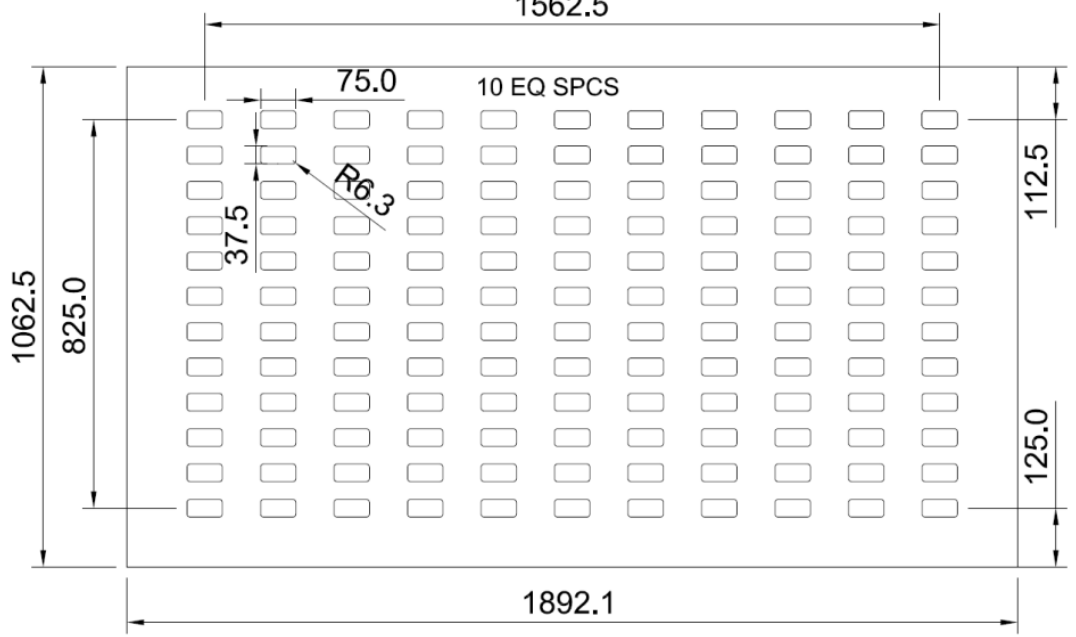

(a) Outer plate

1406.3

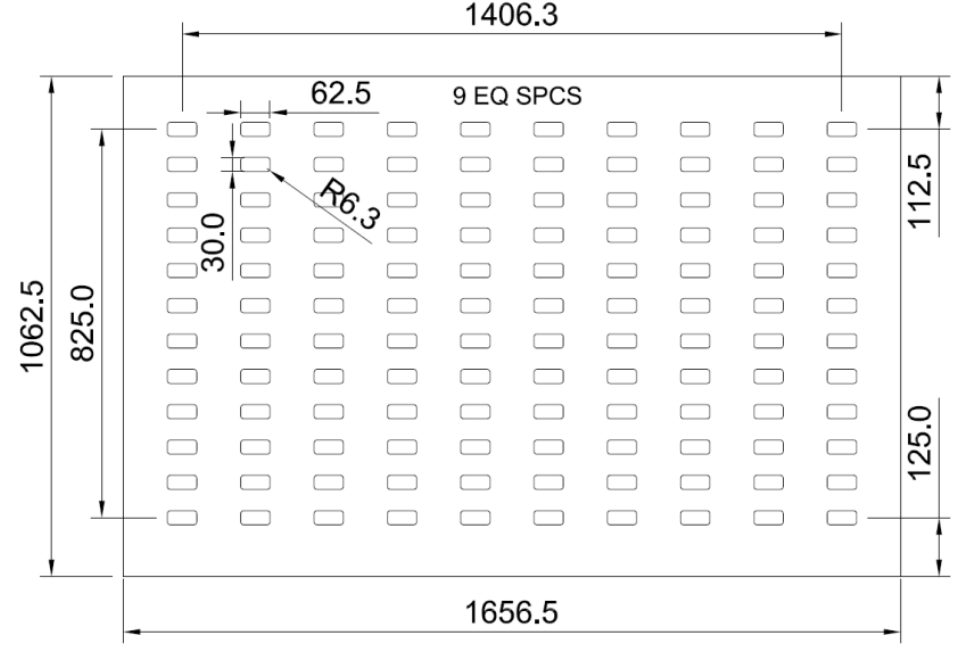

(b) Inner plate

Fig.2. Dimensions of the outer and inner porous plate in model scale (Unit: $\mathrm{mm}$ ). 


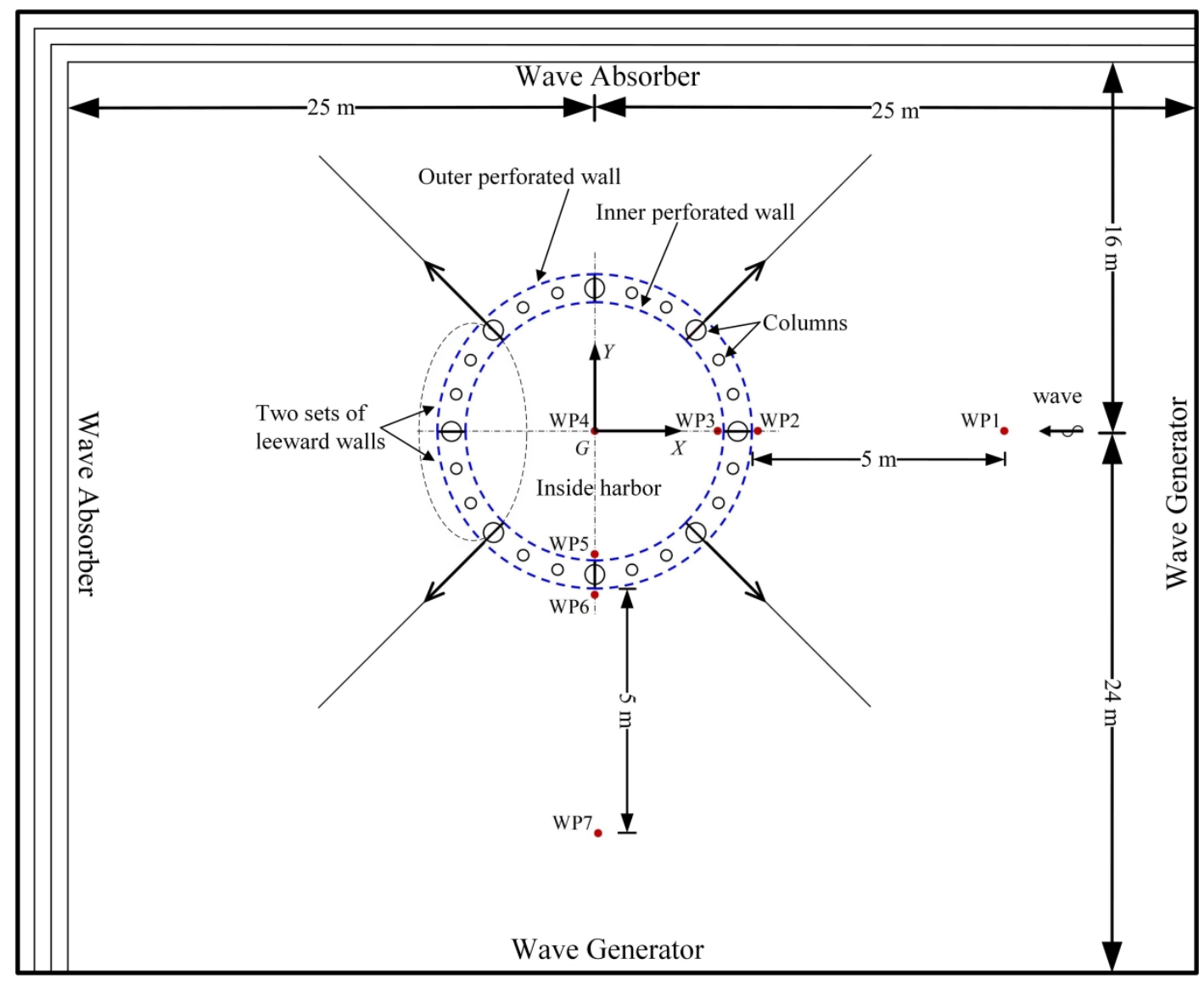

Fig.3. Experimental set-up. 


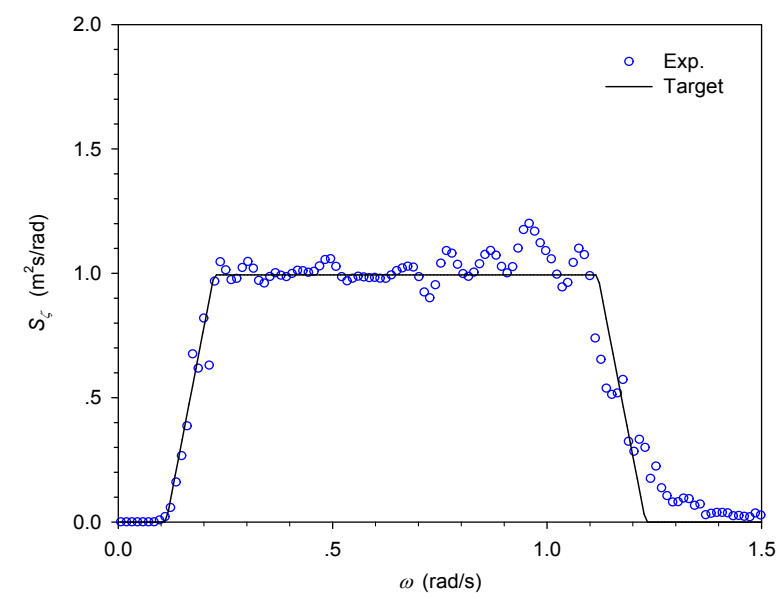

(a) White noise wave

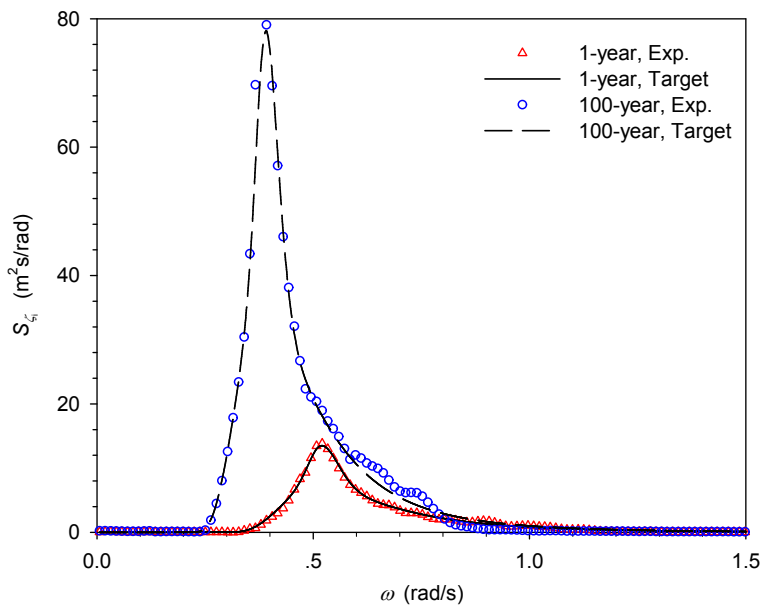

(b) 1-year wave and 100-year wave

Fig.4. Calibration of the incident wave spectra. 


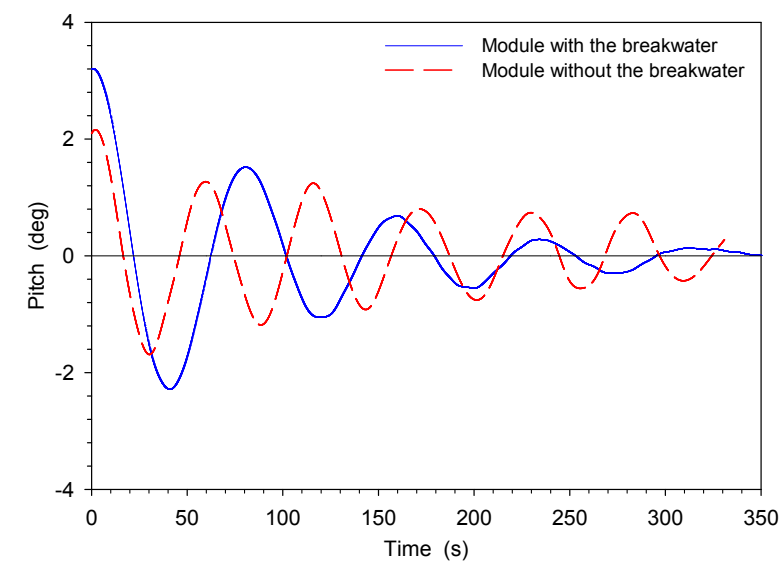

Fig.5. Free decay curves of the pitch motion of the module. 


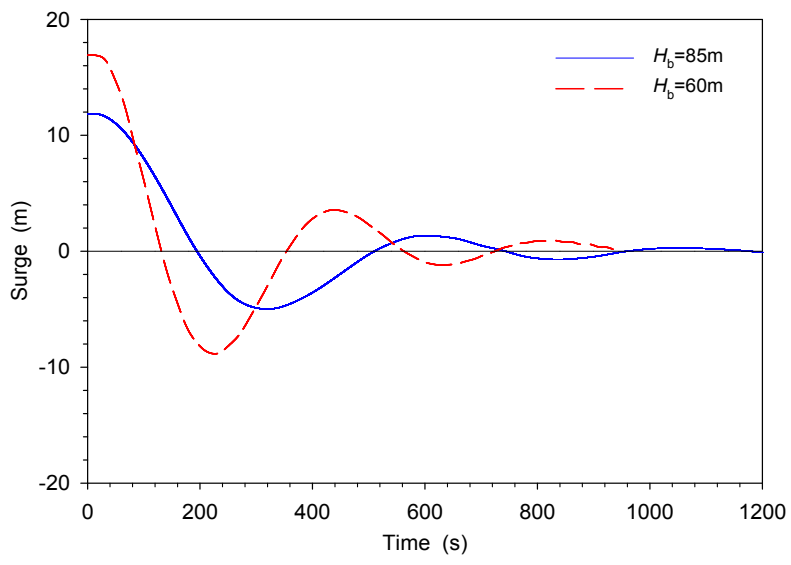

Fig.6. Free decay curves of the surge motion of the VLFS. 


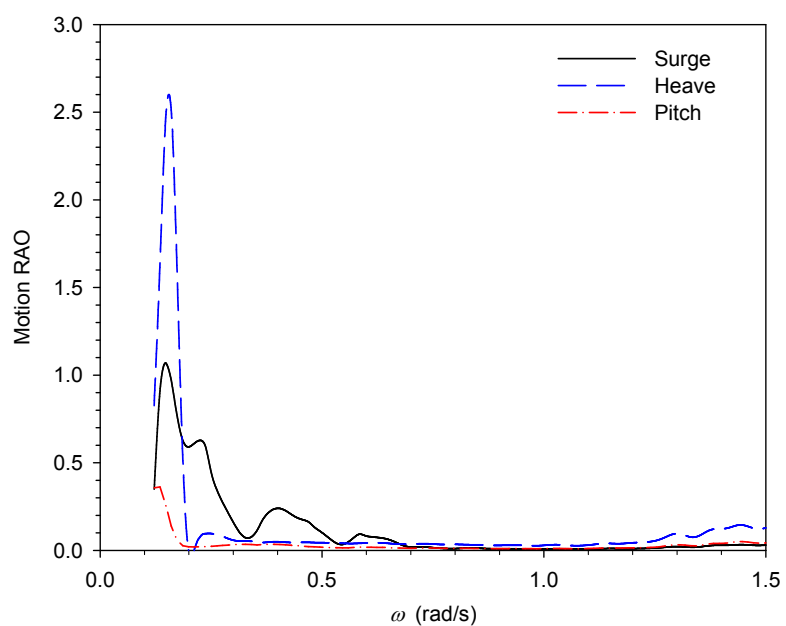

Fig.7. Transfer functions of the motions of the VLFS (Case 1). 


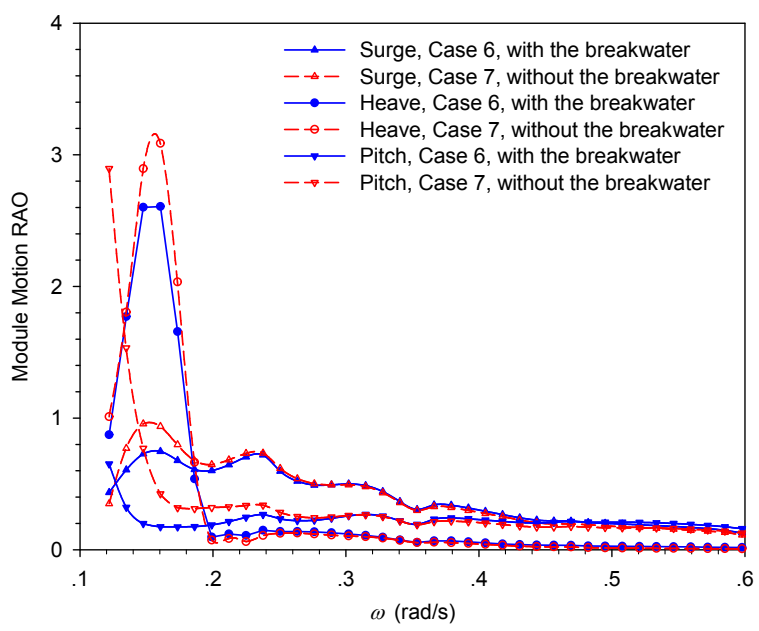

Fig.8. Transfer functions of the motions of the module. 


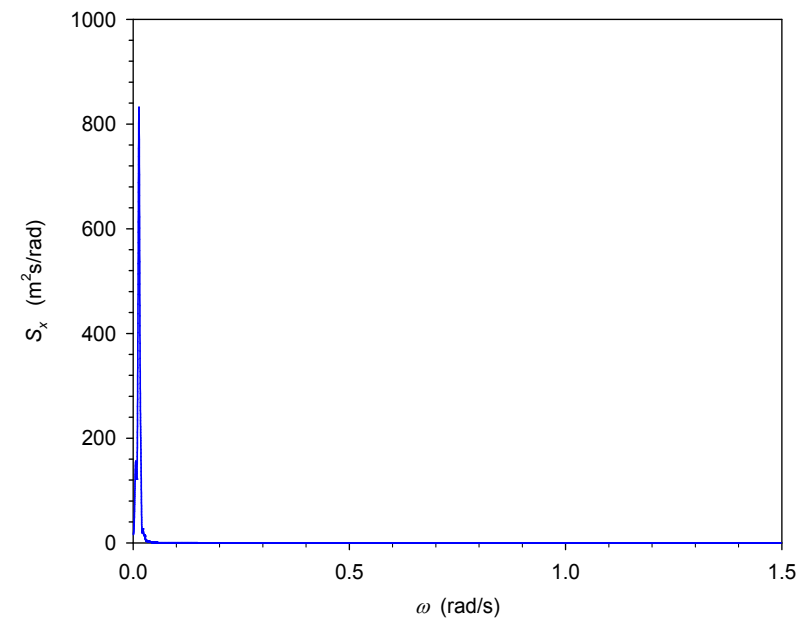

(a) Surge

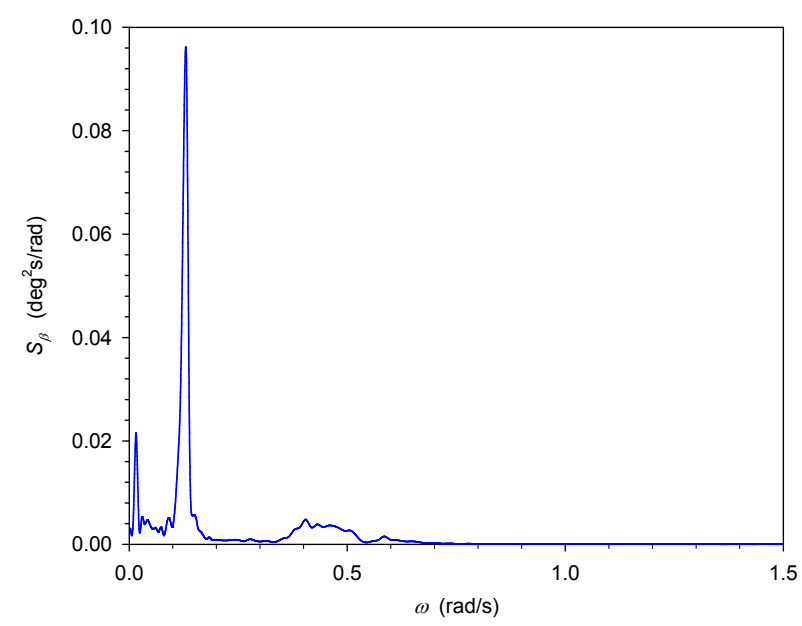

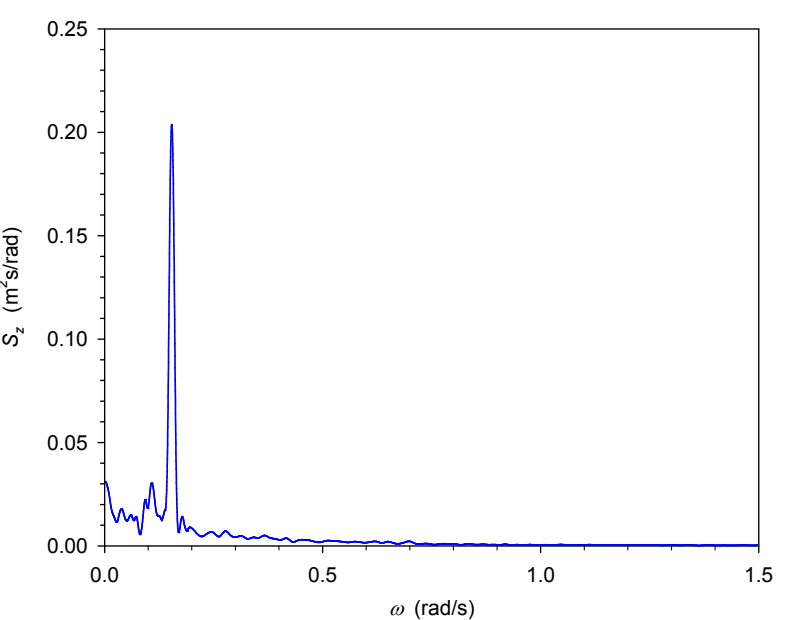

(b) Heave

(c) Pitch

Fig.9. Power spectra of the surge, heave, and pitch motions (Case 2, 1-year). 


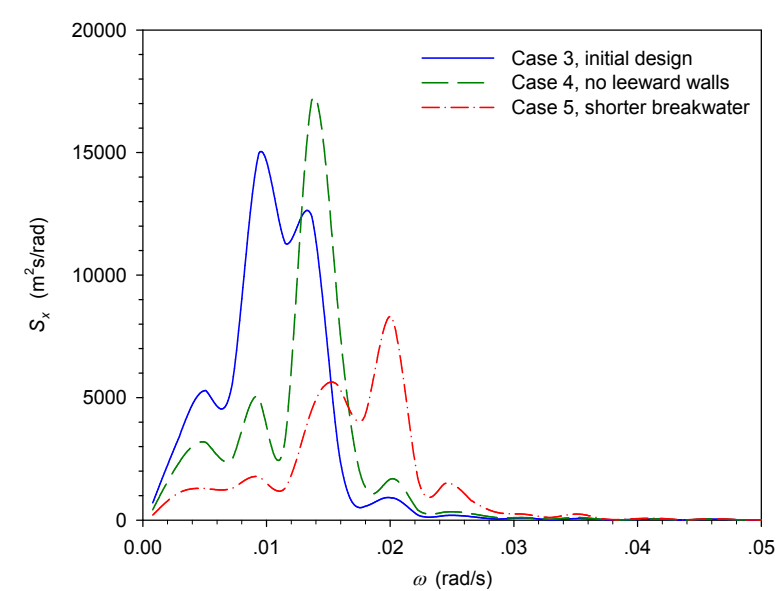

(a) Surge

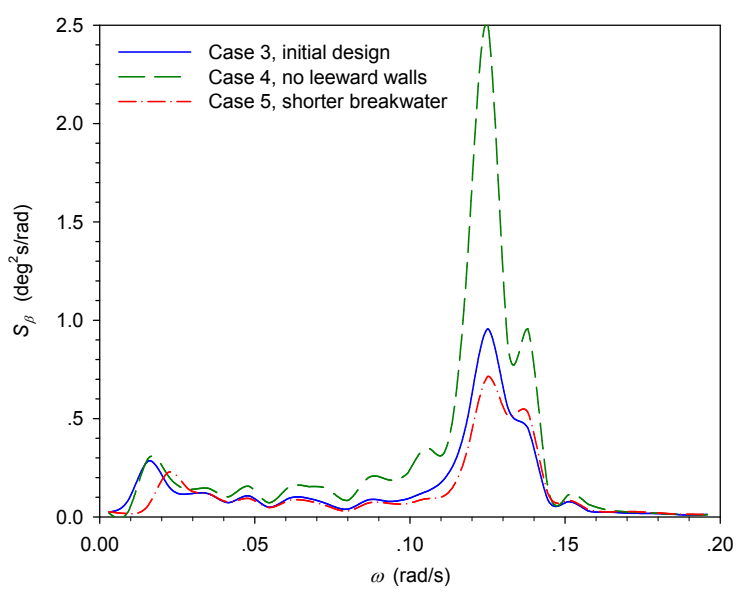

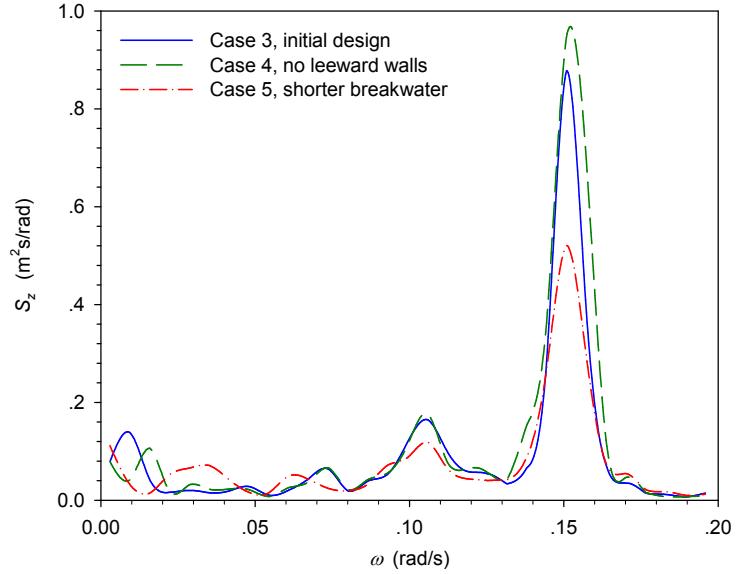

(b) Heave

(c) Pitch

Fig.10. Comparison of the power spectra of the LF motions for the VLFS with different breakwaters (100-year). 


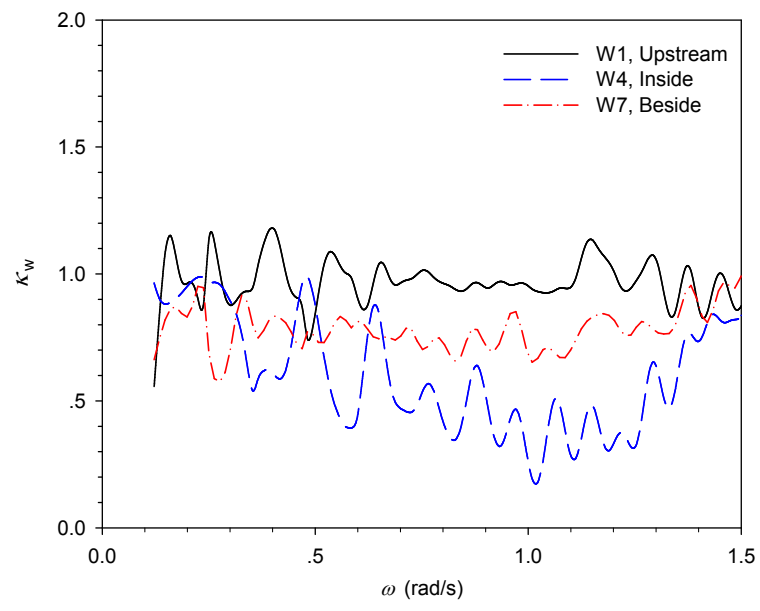

Fig.11. Transfer functions of the upstream, inside, and lateral waves of the VLFS (Case 1). 


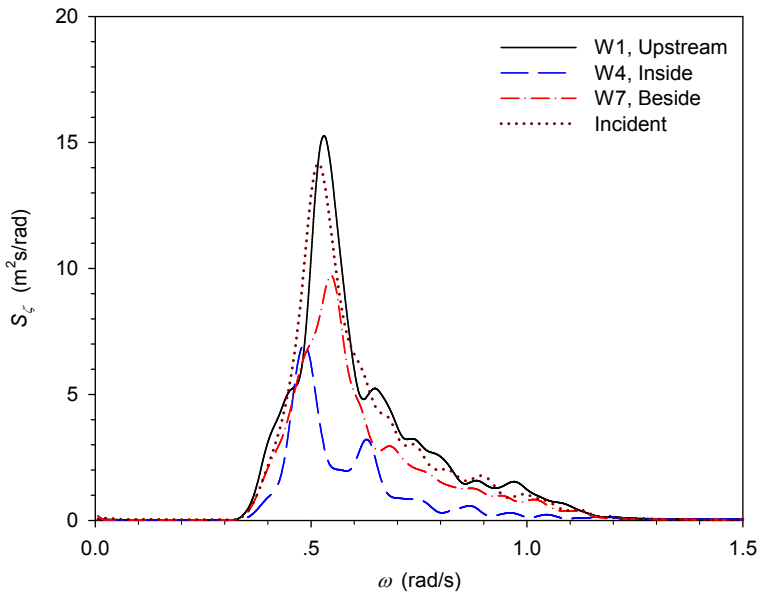

(a) Case 2, 1-year

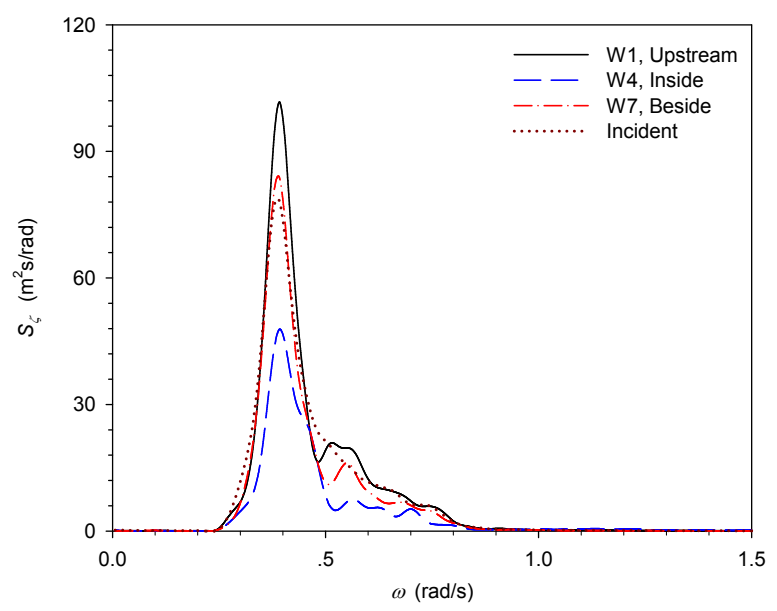

(b) Case 3, 100-year

Fig.12. Comparison of the upstream, inside, and lateral wave spectra of the VLFS with the incident wave. 


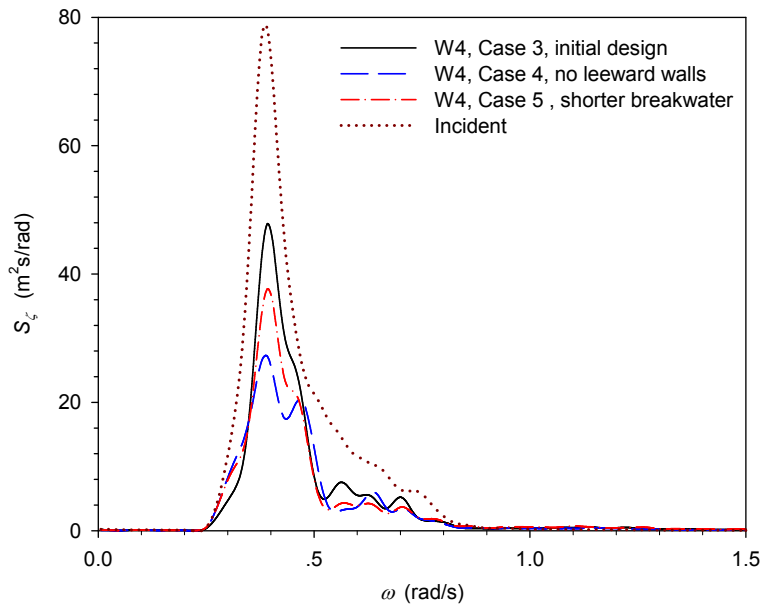

Fig.13. Comparison of the wave spectra in the inside harbor for the VLFS with different breakwaters (100-year). 


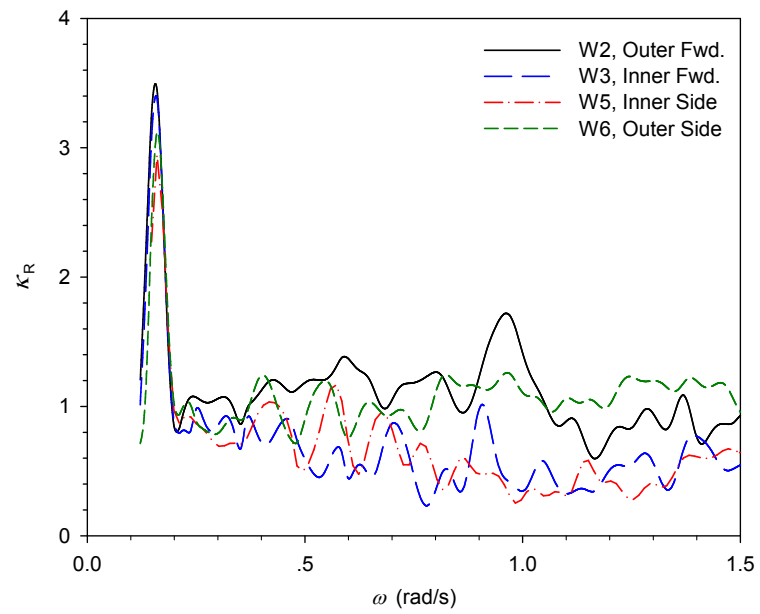

Fig.14. Transfer functions for the wave run-ups at various locations of the VLFS (Case 1). 


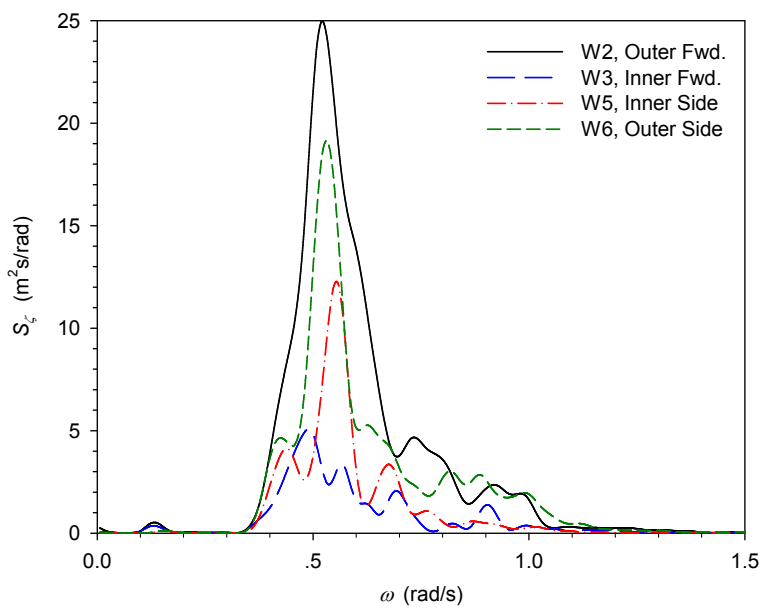

(a) Case 2, 1-year

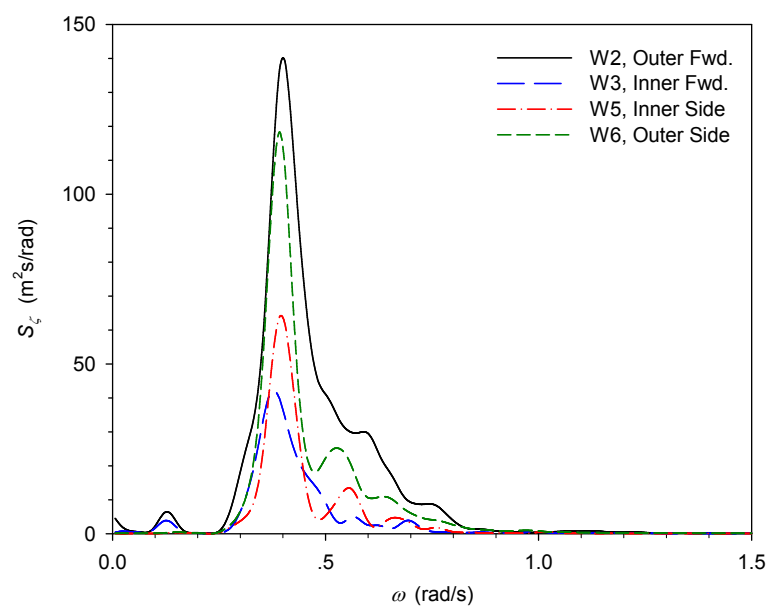

(b) Case 3, 100-year

Fig.15. Spectra of the wave run-ups at various locations of the VLFS. 


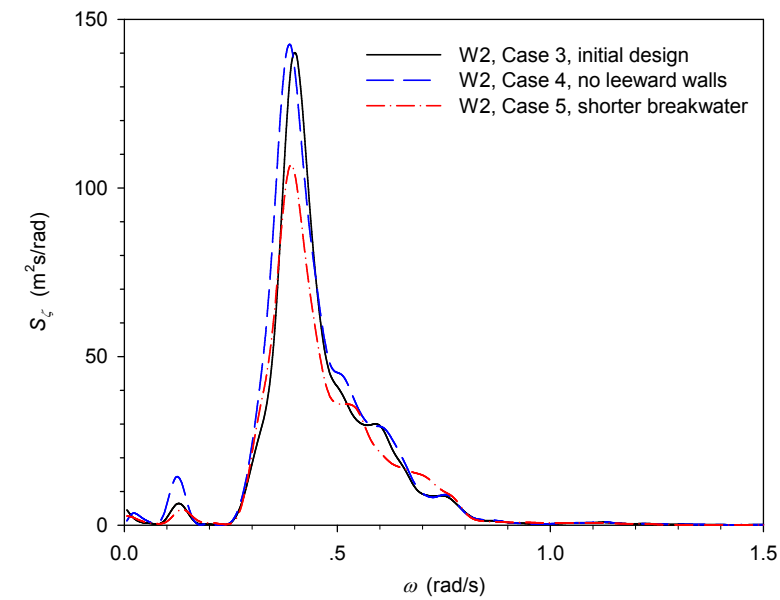

(a) Forward outer wave run-up W2

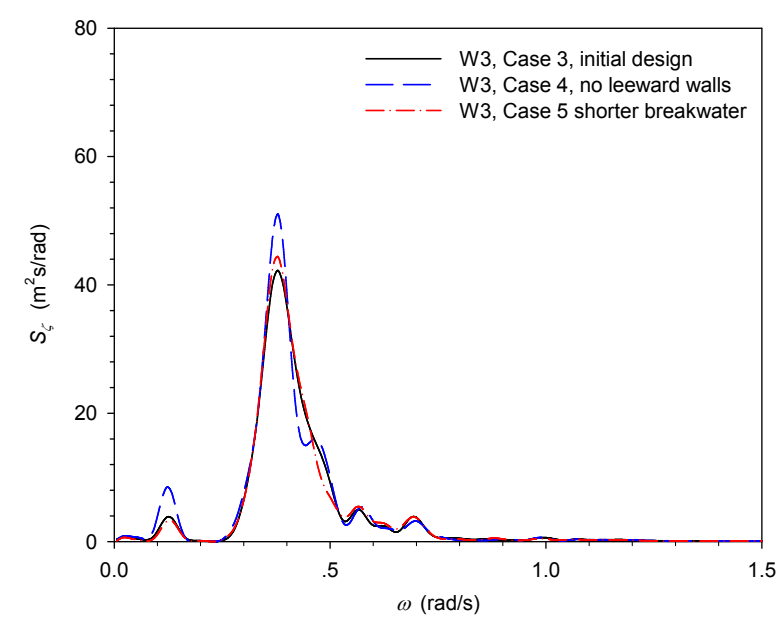

(c) Forward inner wave run-up W3

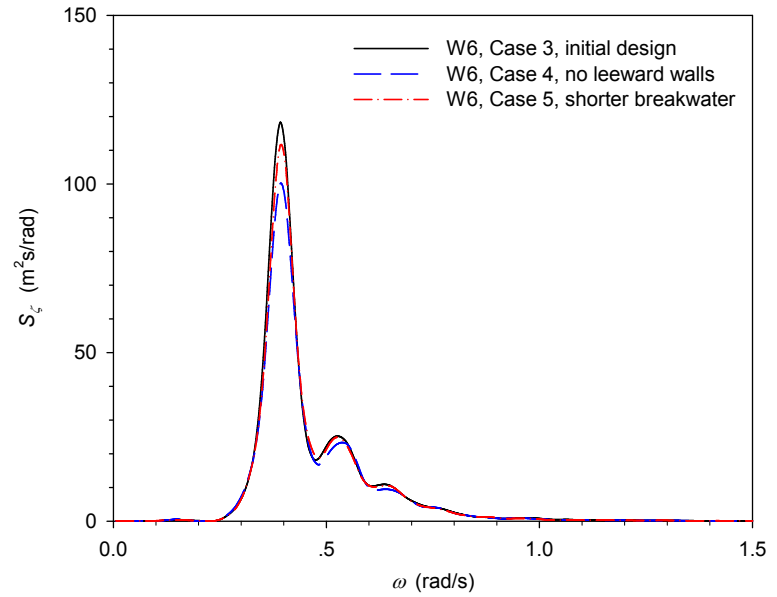

(b) Lateral outer wave run-up W6

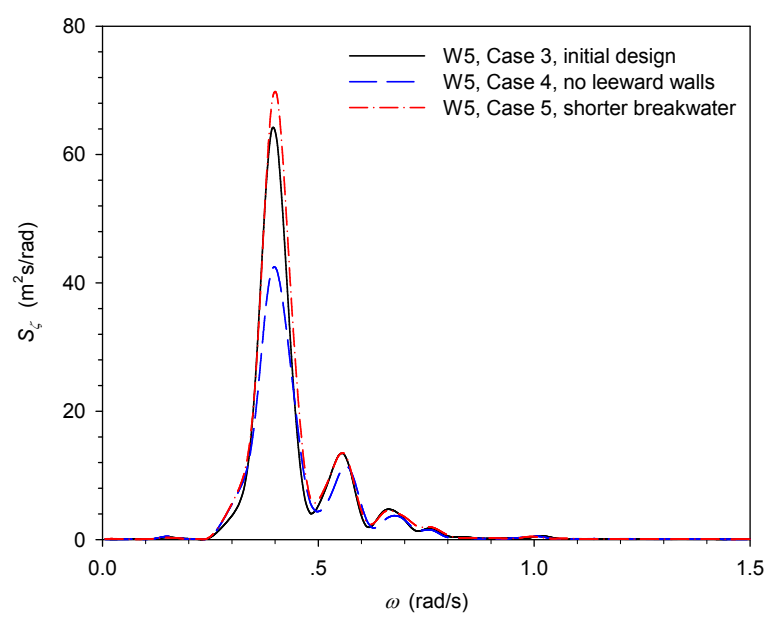

(d) Lateral inner wave run-up W5

Fig.16. Spectra of the outer and inner wave run-ups of the VLFS for different breakwaters (100-year). 